\title{
Effect of calcium substitution on superconductivity and hole concentration in $\mathrm{La}_{1.5} \mathrm{Ba}_{1.5} \mathrm{Cu}_{3} \mathrm{O}_{z}$
}

\author{
NIKESH A SHAH, D G KUBERKAR, B T SAVALIA, M R GONAL ${ }^{\dagger}$, RAM PRASAD ${ }^{\dagger}$ and \\ R G KULKARNI*
}

Department of Physics, Saurashtra University, Rajkot 360005 , India

${ }^{\dagger}$ Metallurgy Division, Bhabha Atomic Research Centre, Mumbai 400 085, India

MS received 17 June 1998

\begin{abstract}
The superconducting properties of single phase $\mathrm{La}_{1.5-x} \mathrm{Ca}_{x+y} \mathrm{Ba}_{1.5-y} \mathrm{Cu}_{3} \mathrm{O}_{z}, 0.0 \leq x \leq 0.60$ (LC) and $0.0 \leq y \leq 0.70(\mathrm{CB})$, compounds with tetragonal triple-perovskite structure are studied, using X-ray diffraction for their resistivity, a.c. susceptibility, and oxygen-content. $\mathrm{La} \mathrm{a}_{1.5-x} \mathrm{Ca}_{x} \mathrm{Ba}_{1.5} \mathrm{Cu}_{3} \mathrm{O}_{2}$ (LC) samples, $0.15 \leq x$ $\leq 0.60$, are superconducting with $T_{\mathrm{c}}^{R=0}$ between 40 and $74 \mathrm{~K}$. With the increase in $x$, the oxygen content, hole concentration in the $\mathrm{CuO}_{2}$ layers as well as the $T_{\mathrm{c}}$ increase. It is interesting to find that although the hole concentration and oxygen stoichiometry of the $\mathrm{LaCa}_{0.5+y} \mathrm{Ba}_{1.5-y} \mathrm{Cu}_{3} \mathrm{O}_{z}$ (CB) compounds increase with the increase in $y$, the $T_{c}^{R=0}$ remains nearly constant around $74 \mathrm{~K}$ for $y=0.0-0.70$. A correlation exists between the $T_{c}$ and the hole concentration for $L C$ and $C B$ compounds.
\end{abstract}

Keywords. Perovskite structure; oxygen content; hole concentration.

\section{Introduction}

The superconducting system $\mathrm{LaCaBaCu}_{3} \mathrm{O}_{z}$ (abbreviated as La-1113) has been the subject of many investigations (De Leeuw et al 1988; Fu et al 1988; Engelsberg 1991; Gunasekaran et al 1993; Leu et al 1996; Yuan et al 1996), as it can be synthesized by following different stoichiometric compositions as the starting material. This La-1113 has a superconducting transition temperature $\left(T_{c}\right)$ of nearly $80 \mathrm{~K}$, with a tetragonal triple-perovskite structure similar to tetragonal $\mathrm{YBa}_{2} \mathrm{Cu}_{3} \mathrm{O}_{7-\delta}(\mathrm{Y}-123)$ (Katano et al 1987).

Recently it has been observed (Leu et al 1996; Yuan et al 1996) that a simultaneous substitution by $\mathrm{Ca}$ or $\mathrm{Sr}$ for $\mathrm{La}$ as well as $\mathrm{Ba}$ in the $\mathrm{La}_{1.5-x / 2}(\mathrm{Ca} / \mathrm{Sr})_{x} \mathrm{Ba}_{1.5-x / 2}$ $\mathrm{Cu}_{3} \mathrm{O}_{2}$ exhibits superconductivity for $0.15 \leq x \leq 0.8$ showing maximum $T_{\text {c }}$ of $78 \mathrm{~K}$ for $\mathrm{Ca}$ and $48 \mathrm{~K}$ for $\mathrm{Sr}$ at $x=0.45-0.75$. To date no attempt has been made to approach La-1113 superconducting phase by replacing $\mathrm{La}$ by $\mathrm{Ca}$ in the $\mathrm{La}_{1.5} \mathrm{Ba}_{1.5} \mathrm{Cu}_{3} \mathrm{O}_{2}$ nonsuperconductor as $\mathrm{La}_{1.5-x} \mathrm{Ca}_{x} \mathrm{Ba}_{1.5} \mathrm{Cu}_{3} \mathrm{O}_{z}$ up to $x=0.5$ (LC), and then substituting $\mathrm{Ca}$ for $\mathrm{Ba}$ in $\mathrm{LaCa}_{0.5+y} \mathrm{Ba}_{1 \cdot 5-y} \mathrm{Cu}_{3} \mathrm{O}_{z}$ (CB).

In this paper, we report the syntheses of $\mathrm{La}_{1.5-x}$ $\mathrm{Ca}_{x} \mathrm{Ba}_{1.5} \mathrm{Cu}_{3} \mathrm{O},(x=0.0-0.60)$ (LC) and $\mathrm{LaCa}_{0.5+y} \mathrm{Ba}_{1.5-y}$ $\mathrm{Cu}_{3} \mathrm{O}_{2}(y=0.0-0.70)$ (CB) systems. These systems are studied by $\mathrm{X}$-ray diffraction for their oxygen stoichiometry, a.c. susceptibility, and resistivity. The interrelationship between the superconductivity, dopant valency and variation in their oxygen content is dis-

*Author for correspondence cussed in relation to the hole concentration in these systems.

\section{Experimental}

A series of compounds having the compositions $\mathrm{La}_{1.5-x} \mathrm{Ca}_{x} \mathrm{Ba}_{1.5} \mathrm{Cu}_{3} \mathrm{O}_{z}(x=0.0-0.60)$ and $\mathrm{LaCa}_{9.5+y} \mathrm{Ba}_{1.5-y} \mathrm{Cu}_{3} \mathrm{O}_{z}$ $(y=0.0-0.70)$ were prepared by solid state route under identical conditions. Stoichiometric quantities of finely powdered $\mathrm{La}_{2} \mathrm{O}_{3}, \mathrm{BaCO}_{3}, \mathrm{CuO}$, and $\mathrm{CaCO}_{3}$ (all $99.98 \%$ pure) were thoroughly mixed and heated in air at $950^{\circ} \mathrm{C}$ for $24 \mathrm{~h}$ in a platinum crucible. This reacted powder was reground and reheated in air at $950^{\circ} \mathrm{C}$ for further $24 \mathrm{~h}$ to obtain a homogeneous single phase sample. The black product obtained was pulverized and cold-pressed into pellets which were sintered at $950^{\circ} \mathrm{C}$ for $12 \mathrm{~h}$ in oxygen atmosphere, followed by slow cooling at the rate of $5^{\circ} \mathrm{C} \mathrm{min}^{-1}$ until it reached room temperature. To obtain oxygenated samples, these pellets were annealed under oxygen flow at $500^{\circ} \mathrm{C}$ for $24 \mathrm{~h}$, followed by a slow cooling at the rate of $1^{\circ} \mathrm{C} \mathrm{min}^{-1}$ until it reached room temperature.

All samples were characterized at room temperature by $\mathrm{X}$-ray diffraction using $\mathrm{CuK} \alpha$ radiation. The $\mathrm{X}$-ray analysis revealed that all the samples were indeed single phase. The stoichiometric composition of the constituents in the samples was confirmed by EDAX analysis using JEOL scanning electron microscope. The oxygen stoichiometry of the samples was determined by iodometric titration technique. Resistivity was measured as 
a function of temperature on regularly-shaped samples, using the standard four-probe method. The a.c. susceptibility measurements were accomplished in a system with a lock-in-amplifier, and an APD cryocooler.

\section{Results and discussion}

Single phase materials were obtained between $0.0 \leq x \leq 0.60$, and $0.0 \leq y \leq 0.70$ for LC and CB systems, respectively, as shown by the XRD patterns. Figure 1 shows the typical XRD patterns of $\mathrm{La}_{1.5-x} \mathrm{Ca}_{x} \mathrm{Ba}_{1.5} \mathrm{Cu}_{3} \mathrm{O}_{z}$ (LC) for $x=0.0,0 \cdot 10,0.20,0.50$, and $\mathrm{LaCa}_{1.5+y} \mathrm{Ba}_{1.5-y}$ $\mathrm{Cu}_{3} \mathrm{O}_{z}(\mathrm{CB})$ for $y=0.50$. The observed $\mathrm{X}$-ray diffraction peaks modelled by modified Gaussian functions and refined unit cell parameters, and calculated using the standard least squares programme, are listed in table 1 for LC and CB samples. All the LC and CB samples maintain a tetragonal triple-perovskite structure. The a and $c$ parameters and the unit cell volume decrease with increasing concentration, $x$ (table 1 ), because $\mathrm{La}^{3+}$ with larger ionic radius $(1.02 \AA)$ is replaced by the smaller $\mathrm{Ca}^{2+}$ ionic radius $(0.99 \AA)$ in LC. Likewise, the a and c parameters as well as the unit cell volume of $\mathrm{CB}$ samples decrease with increasing Ca content, $y$, (table 1), as $\mathrm{Ba}^{2+}$ ion with larger ionic radius $(1.34 \AA)$ is replaced by the smaller $\mathrm{Ca}^{2+}$ ion $(0.99 \AA)$. Similar results have been reported for the $\mathrm{La}_{4-x} \mathrm{Ca}_{x} \mathrm{Ba}_{3} \mathrm{Cu}_{7} \mathrm{O}_{2}$ (Wu et al 1993a), $\mathrm{La}_{3} \mathrm{Ba}_{4-x} \mathrm{Ca}_{x} \mathrm{Cu}_{7} \mathrm{O}_{z}$ (Wu et al 1993b), and $\mathrm{La}_{3-x} \mathrm{Ca}_{2 \mathrm{r}}$ $\mathrm{Ba}_{3-x} \mathrm{Cu}_{6} \mathrm{O}_{z}$ (Leu et al 1996) series.

The values of oxygen content, $z$, of the LC and CB samples, as determined by an iodometric titration technique, are listed in table 2 . The effective $\mathrm{Cu}$ valence $(2+p)$ or the hole concentration $(p)$ per $[\mathrm{Cu}-\mathrm{O}]$ unit was calculated from these data and is included in table 2. It is evident from table 2 that the oxygen content $(z)$ as well as the hole concentration $(p)$ of LC and CB series increase with the increasing $\mathrm{Ca}$ concentration, suggesting that $\mathrm{Ca}^{2+}$ acts as a hole dopant. The oxygen stoichiometry of $\mathrm{LC}$ and $\mathrm{CB}$ compounds results from two counter-balanced effects: charge balance and hole doping.

Thus, increasing $\mathrm{Ca}^{2+}(0.99 \AA)$ ion substitution for $\mathrm{La}^{3+}(1.02 \AA)$ ions results in a decrease in the positive charge, which can be compensated to some extent by increasing the holes which leads to the net increase in the oxygen stoichiometry, as observed. A noteworthy fact is that while both $p$ and $z$ of LC and CB series increase with the increase in $\mathrm{Ca}$ concentration similar to $\mathrm{La}_{3} \mathrm{Ba}_{4-x} \mathrm{Ca}_{x} \mathrm{Cu}_{7} \mathrm{O}_{z}$ (Wu et al 1993b), for $\mathrm{La}_{1.5-x / 2} \mathrm{Ca}_{x}$ $\mathrm{Ba}_{1.5-x / 2} \mathrm{Cu}_{3} \mathrm{O}_{z}$ (Leu et al 1996), $\mathrm{La}_{1.5-x / 2} \mathrm{Sr}_{x} \mathrm{Ba}_{1.5-x / 2} \mathrm{Cu}_{3} \mathrm{O}_{z}$ (Yuan et al 1996), and $\mathrm{La}_{4-x} \mathrm{Ca}_{x} \mathrm{Ba}_{3} \mathrm{Cu}_{7} \mathrm{O}_{z}$ (Wu et al 1993a) series, $p$ increases and $z$ decreases.

Typical resistivity results of LC and CB samples are given in figures 2 and 3 , respectively. The resistive superconducting transition temperatures at zero resistance,

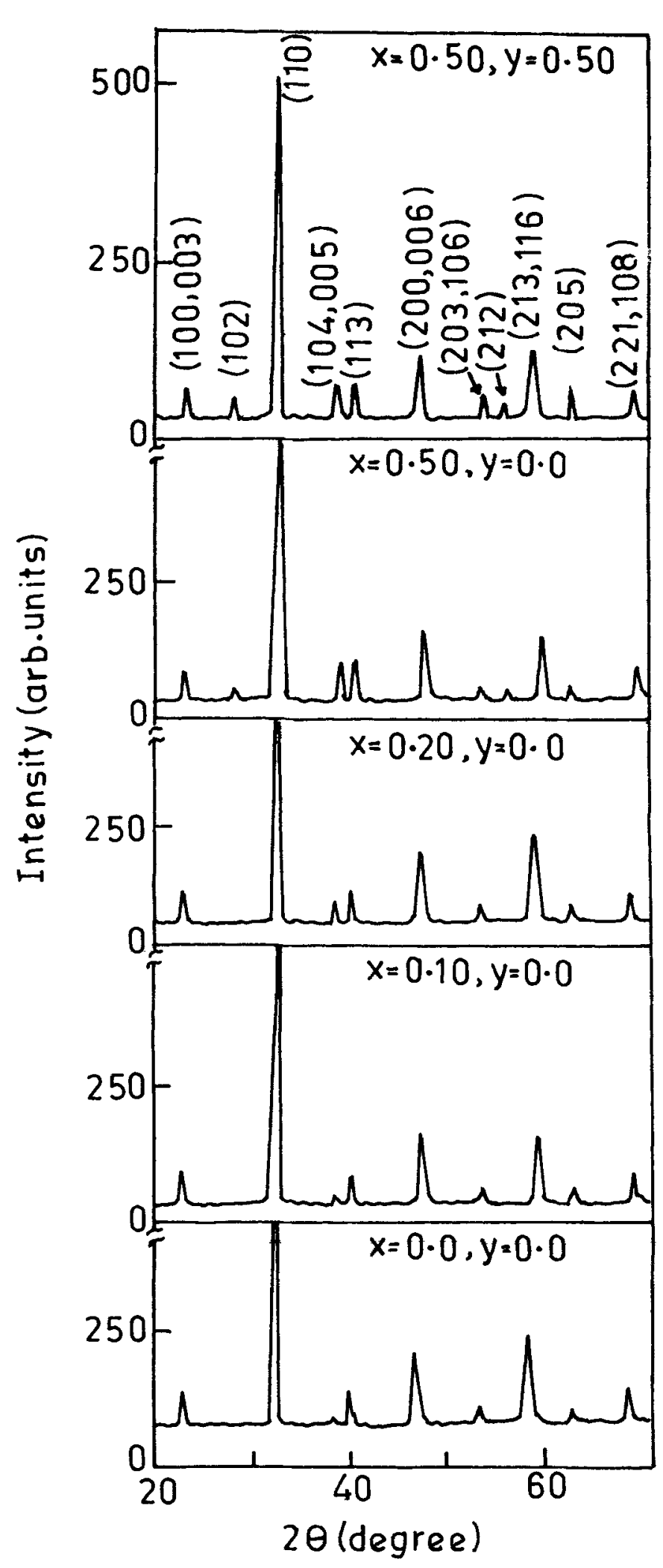

Figure 1. XRD patterns of $\mathrm{La}_{1.5-x} \mathrm{Ca}_{x} \mathrm{Ba}_{1.5} \mathrm{Cu}_{3} \mathrm{O}_{z}$ (LC) for $x=0.0,0 \cdot 1,0 \cdot 2,0.5$ and $\mathrm{LaCa}_{0.5+y} \mathrm{Ba}_{15-y} \cdot \mathrm{Cu}_{3} \mathrm{O}_{2}$ (CB) for $y=0.5$. 
Table 1. Values of unit cell parameters, unit cell volume and density of $\mathrm{La}_{1.5-x} \mathrm{Ba}_{1.5-y} \mathrm{Ca}_{x+y} \mathrm{Cu}_{3} \mathrm{O}_{z}$ system.

\begin{tabular}{|c|c|c|c|c|}
\hline \multirow{2}{*}{$\begin{array}{l}\text { Sample } \\
(x, y)\end{array}$} & \multicolumn{2}{|c|}{ Unit cell parameters $(\AA)$} & \multirow{2}{*}{$\begin{array}{l}\text { Volume, } \\
V\left(\AA^{3}\right)\end{array}$} & \multirow{2}{*}{$\begin{array}{l}\text { X-ray density } \\
\left(\mathrm{g} / \mathrm{cm}^{3}\right)\end{array}$} \\
\hline & $a, b$ & $\mathrm{c}$ & & \\
\hline$(0.00,0.00)$ & $3.926(3)$ & $11 \cdot 753(9)$ & $181 \cdot 1546(11)$ & $6.503(3)$ \\
\hline$(0 \cdot 10,0.00)$ & $3.908(3)$ & $11 \cdot 736(9)$ & $179 \cdot 2376(11)$ & $6.488(3)$ \\
\hline$(0.15,0.00)$ & $3.899(3)$ & $11.732(9)$ & $178 \cdot 3522(11)$ & $6 \cdot 486(3)$ \\
\hline$(0.20,0.00)$ & 3.891(3) & $11.726(9)$ & $177.5302(11)$ & $6.478(3)$ \\
\hline$(0.25,0.00)$ & $3 \cdot 888(3)$ & $11.720(9)$ & $177 \cdot 1659(11)$ & $6 \cdot 448(3)$ \\
\hline$(0.35,0.00)$ & $3.885(3)$ & $11.703(9)$ & $176.6360(11)$ & $6 \cdot 382(3)$ \\
\hline$(0.40,0.00)$ & $3 \cdot 884(3)$ & $11.693(9)$ & $176 \cdot 3942(11)$ & $6 \cdot 348(3)$ \\
\hline$(0.45,0.00)$ & $3.881(3)$ & $11.686(9)$ & $176 \cdot 0164(11)$ & $6 \cdot 314(3)$ \\
\hline$(0.50,0.00)$ & $3.878(3)$ & $11.666(9)$ & $175 \cdot 4436(11)$ & $6 \cdot 294(3)$ \\
\hline$(0.60,0.00)$ & $3.899(3)$ & $11 \cdot 701(9)$ & $177 \cdot 8809(11)$ & $6 \cdot 099(3)$ \\
\hline$(0.50,0.10)$ & $3.874(3)$ & $11 \cdot 654(9)$ & $174.9018(11)$ & $6 \cdot 228(3)$ \\
\hline$(0.50,0.20)$ & $3 \cdot 867(3)$ & $11.640(9)$ & 174.0609(11) & $6 \cdot 169(3)$ \\
\hline$(0.50,0.30)$ & $3.863(3)$ & $11.631(9)$ & $173 \cdot 5667(11)$ & $6 \cdot 098(3)$ \\
\hline$(0.50,0.40)$ & $3.858(3)$ & $11 \cdot 613(9)$ & $172 \cdot 8498(11)$ & $6 \cdot 041(3)$ \\
\hline$(0.50,0.50)$ & $3.850(3)$ & $11.560(9)$ & $171 \cdot 3481(11)$ & $5.995(3)$ \\
\hline$(0.50,0.60)$ & $3 \cdot 824(3)$ & $11.483(9)$ & $167.9156(11)$ & $5 \cdot 982(3)$ \\
\hline$(0.50,0.70)$ & $3.803(3)$ & $11 \cdot 419(9)$ & $165 \cdot 1508(11)$ & $5 \cdot 984(3)$ \\
\hline
\end{tabular}

Table 2. Values for oxygen content, hole concentration and $T_{\mathrm{c}}$ of $\mathrm{La}_{1.5-x} \mathrm{Ba}_{1.5-y} \mathrm{Ca}_{x+y} \mathrm{Cu}_{3} \mathrm{O}_{z}$ system.

\begin{tabular}{|c|c|c|c|c|}
\hline $\begin{array}{l}\text { Sample } \\
(x, y)\end{array}$ & $\begin{array}{l}\text { Resistivity } \\
T_{\mathrm{c}}^{R=0}(\mathrm{~K})\end{array}$ & $\begin{array}{l}\text { A.C. susceptibility } \\
T_{\mathrm{c}}^{\mathrm{ON}}\left(\chi_{\mathrm{ac}}\right)\end{array}$ & $\begin{array}{c}\text { Oxygen } \\
\text { content }(z)\end{array}$ & $\begin{array}{l}\text { Hole concentration } \\
\text { (p) }\end{array}$ \\
\hline$(0.00,0.00)$ & NS & NS & $6 \cdot 55(3)$ & $0.033(3)$ \\
\hline$(0 \cdot 10,0.00)$ & NS & NS & $6.59(3)$ & $0 \cdot 060(3)$ \\
\hline$(0.15,0.00)$ & $40(2)$ & $43(2)$ & $6 \cdot 67(3)$ & $0 \cdot 113(3)$ \\
\hline$(0.20,0.00)$ & $45(2)$ & $48(2)$ & $6 \cdot 72(3)$ & $0 \cdot 147(3)$ \\
\hline$(0.25,0.00)$ & $68(2)$ & $70(2)$ & $6 \cdot 74(3)$ & $0.160(3)$ \\
\hline$(0.35,0.00)$ & $69(2)$ & $72(2)$ & $6 \cdot 79(3)$ & $0.193(3)$ \\
\hline$(0.40,0.00)$ & $70(2)$ & $72(2)$ & $6 \cdot 82(3)$ & $0.213(3)$ \\
\hline$(0.45,0.00)$ & $71(2)$ & $74(2)$ & $6 \cdot 81(3)$ & $0.207(3)$ \\
\hline$(0.50,0.00)$ & $74(2)$ & $76(2)$ & $6.85(3)$ & $0.233(3)$ \\
\hline$(0.60,0.00)$ & $70(2)$ & $73(2)$ & $6 \cdot 74(3)$ & $0.160(3)$ \\
\hline$(0.50,0.10)$ & $74(2)$ & $76(2)$ & $6.90(3)$ & $0.267(3)$ \\
\hline$(0.50,0.20)$ & $73(2)$ & $76(2)$ & $6.92(3)$ & $0 \cdot 280(3)$ \\
\hline$(0.50,0.30)$ & $74(2)$ & $75(2)$ & $6.95(3)$ & $0 \cdot 300(3)$ \\
\hline$(0.50,0.40)$ & $75(2)$ & $77(2)$ & $7.02(3)$ & $0 \cdot 347(3)$ \\
\hline$(0.50,0.50)$ & $75(2)$ & $78(2)$ & $6.99(3)$ & $0.327(3)$ \\
\hline$(0.50,0.60)$ & $71(2)$ & $72(2)$ & $7.05(3)$ & $0.367(3)$ \\
\hline$(0.50,0.70)$ & $60(2)$ & $66(2)$ & $7 \cdot 11(3)$ & $0.406(3)$ \\
\hline
\end{tabular}

NS, Non superconducting

$T_{\mathrm{c}}^{R=0}$, obtained from figures 2 and 3 are listed in table 2 . For $x \leq 0.1 \mathrm{LC}$ samples, a metal to semiconducting type transition is observed. All the other LC samples ( $x=0.15-0.60)$ show a metallic conducting behaviour from $300 \mathrm{~K}$ to the superconducting transition temperature. For $x=0.0$ and 0.1 samples, no $T_{\mathrm{c}}$ is observed. For $0.15 \leq x \leq 0.60$ samples, $T_{c}^{R=0}$ is found between $40 \mathrm{~K}$ and $74 \mathrm{~K}$ (figure 2 ). In the case of $\mathrm{CB}$ series, all samples exhibit metallic to superconducting transitions with almost constant $T_{c}^{R=0} \sim 74 \mathrm{~K}$ for $y=0 \cdot 1-0.5$, and thereafter $T_{\mathrm{c}}^{R=0}$ decreases with increasing $y$ for $y=0.5-0.7$ (table 2).
The temperature dependence of a.c. susceptibility for typical samples of both LC and CB are shown in figures 4 and 5, respectively. The onset critical temperature determined from a.c. susceptibility $T_{\mathrm{c}}^{\mathrm{s}}\left(\chi_{\mathrm{ac}}\right)$ listed in table 2 agrees very well with the resistively found $T_{c}^{R=0}$. This shows the consistency of the measurements and the quality of samples.

Figure 6a shows $T_{c}$ vs oxygen stoichiometry and figure $6 \mathrm{~b}$ shows $T_{\mathrm{c}}$ vs hole concentration of the $\mathrm{LC}$ and $\mathrm{CB}$ series, respectively. A plateau is observed for $T_{c}$ around $74 \mathrm{~K}$. For the sake of comparison and completeness, we 
have also shown in figure $6 a$ the variation of $T_{c}$ with oxygen stoichiometry in $\mathrm{La}_{1.5-x / 2} \mathrm{Ca}_{x} \mathrm{Ba}_{1.5-x / 2} \mathrm{Cu}_{3} \mathrm{O}_{z}$ (LCB) (Leu et al 1996) and $\mathrm{La}_{1.5-x / 2} \mathrm{Sr}_{x} \mathrm{Ba}_{1.5-x / 2} \mathrm{Cu}_{3} \mathrm{O}_{z}$ (LSB) (Yuan et al 1996), and in figure $6 \mathrm{~b}$ the variation of $T_{\mathrm{c}}$ with hole concentration in LCB and LSB. The data for both the systems was taken from Leu et al (1996) and Yuan et al (1996).

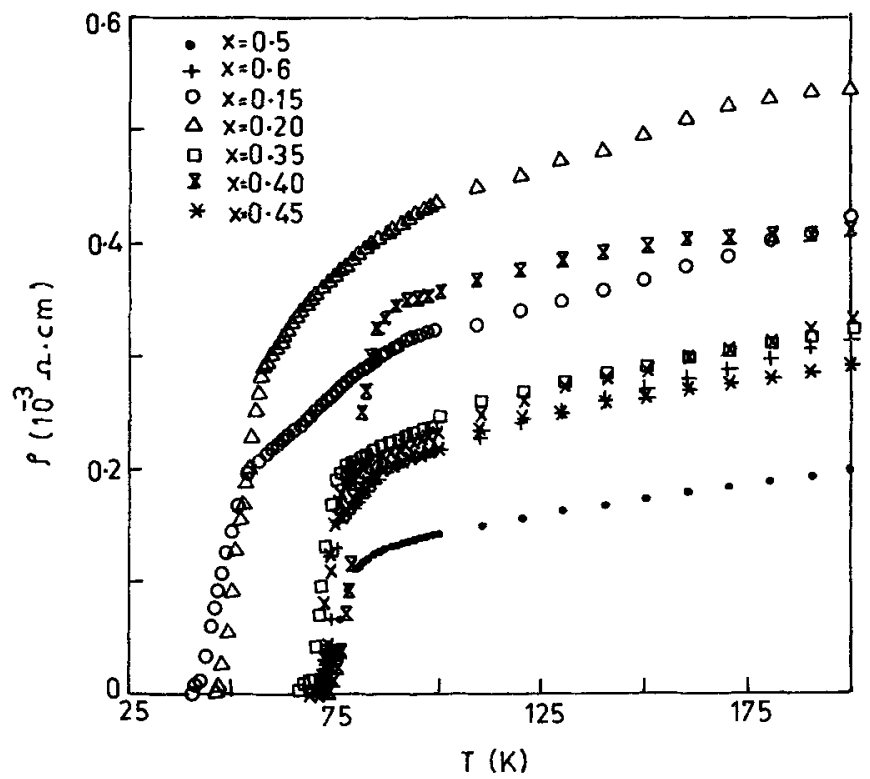

Figure 2. Resistivity vs temperature for $\mathrm{La}_{1 \cdot 5-x} \mathrm{Ca}_{x} \mathrm{Ba}_{1.5} \mathrm{Cu}_{3} \mathrm{O}_{z}$.

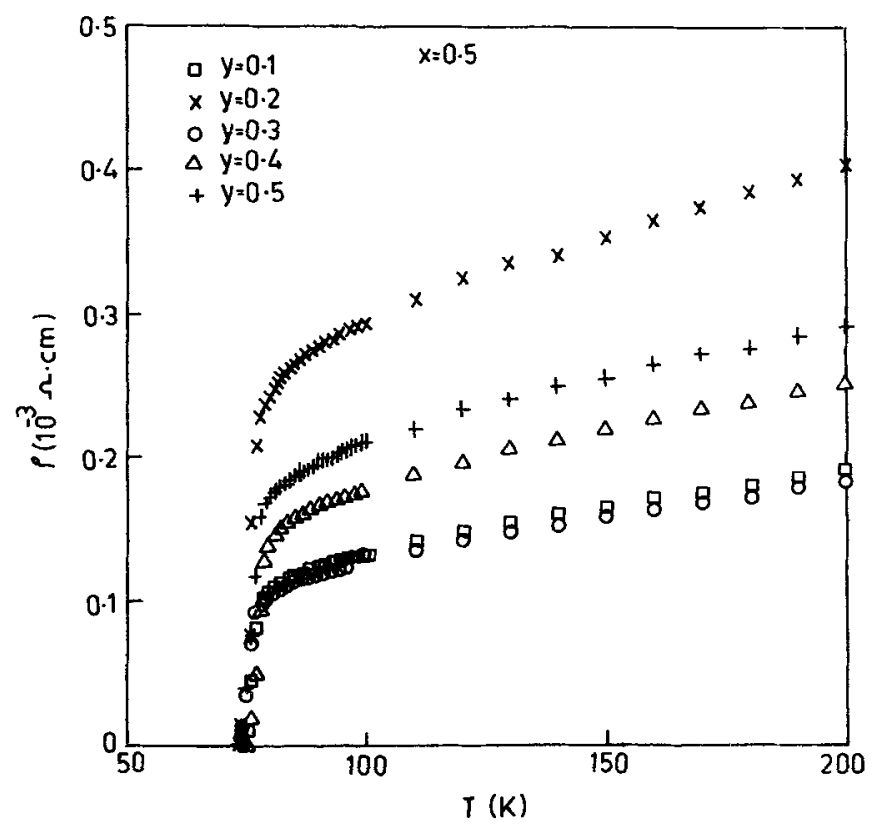

Figure 3. Resistivity vs temperature for $\mathrm{LaCa}_{0.5+y} \mathrm{Ba}_{1 \cdot 5-y} \mathrm{Cu}_{3} \mathrm{O}_{z}$.
It is evident from figure 6a that there is a disagreement between the increase of $T_{\mathrm{c}}$ with oxygen stoichiometries of LC, CB, LCB (Leu et al 1996) and LSB (Yuan et al 1996), respectively. According to present work, $T_{\mathrm{c}}^{R=0}$ of LC compounds increases with increasing $z$ from 6.55 to $6 \cdot 85$, and $T_{\mathrm{c}}^{R=0}$ of CB compounds remains nearly constant

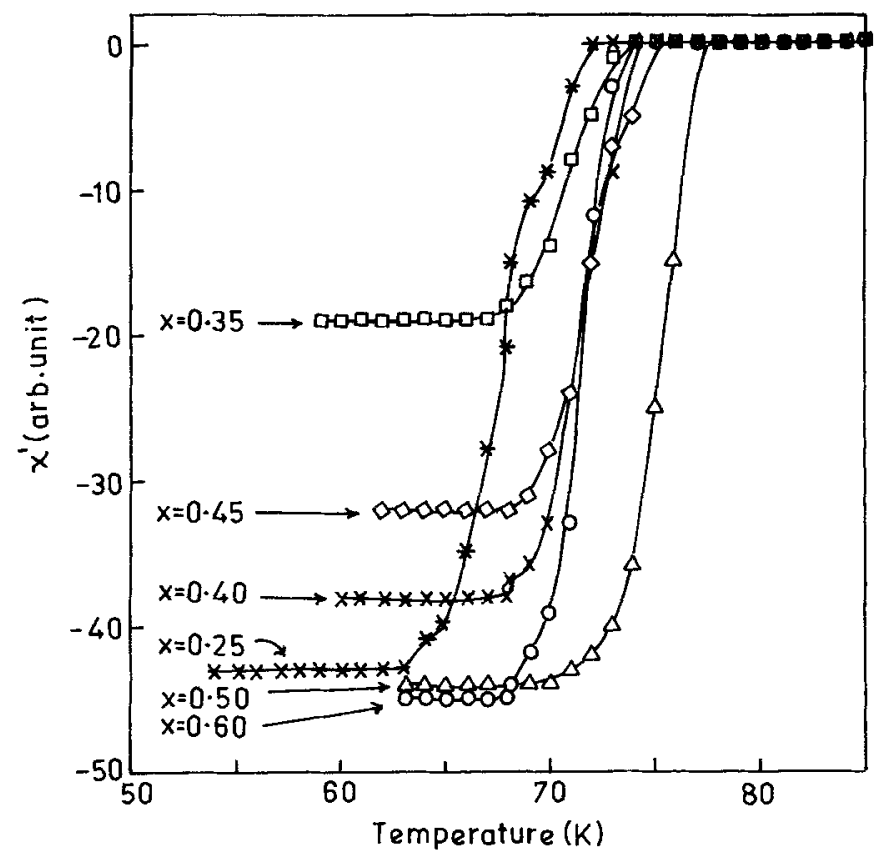

Figure 4. Temperature dependence of a.c. susceptibility for $\mathrm{La}_{1.5-x} \mathrm{Ca}_{x} \mathrm{Ba}_{1.5} \mathrm{Cu}_{3} \mathrm{O}_{z}$.

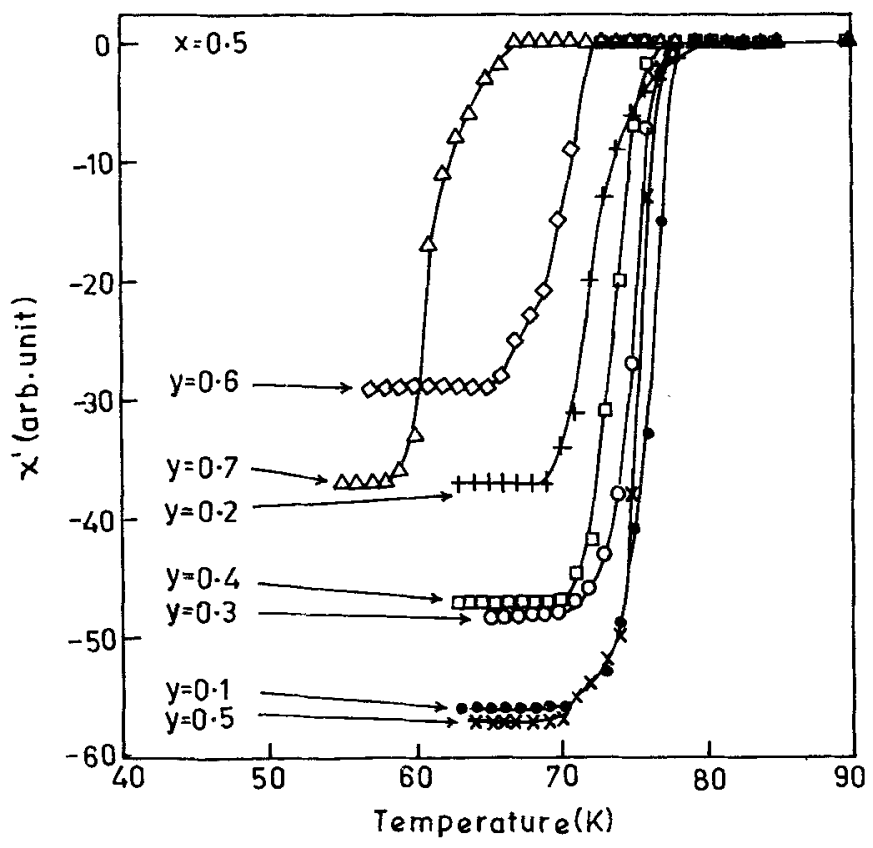

Figure 5. Temperature dependence of a.c. susceptibility for $\mathrm{LaCa}_{0.5+y} \mathrm{Ba}_{1.5-y} \mathrm{Cu}_{3} \mathrm{O}_{z}$. 
despite increase in $z$ from 6.85 to 7.02 , and thereafter it decreases. In contrast, the $T_{c}^{R=0}$ of LCB (Leu et al 1996) and LSB (Yuan et al 1996) compounds increases with decreasing $z$ from 7.15 to 7.04 (figure 6a). There is a similarity in the increase of $T_{\mathrm{c}}$ with hole concentration among LC, CB, LCB (Leu et al 1996) and LSB (Yuan et al 1996) series though the actual variation in $p$ is different for all the compounds.

The lanthanum stoichiometry of LC series is reduced from 1.50 to 0.90 as $x$ increases from 0.0 to 0.60 . Since the lanthanum stoichiometry is greater than one and there is only one $\mathrm{Y}^{3+}$ site in a $\mathrm{YBa}_{2} \mathrm{Cu}_{3} \mathrm{O}_{2}$ triple-perovskite unit cell, some of the $\mathrm{La}^{3+}$ ions must occupy the $\mathrm{Ba}^{2+}$ site for all the LC compounds. As shown in table 2, the hole concentration increases with decreasing lanthanum stoichiometry up to $x=0.50$ and thereafter it decreases for $x=0 \cdot 60$, being off stoichiometry in the LC series.

Similar trend is observed for $T_{\mathrm{c}}^{R=0}$ vs lanthanum stoichiometry (table 2). The $T_{c}^{R=0}$ of $x=0.6$ samples decreases from $74 \mathrm{~K}$ to $70 \mathrm{~K}$ due to decrease in $p$ and
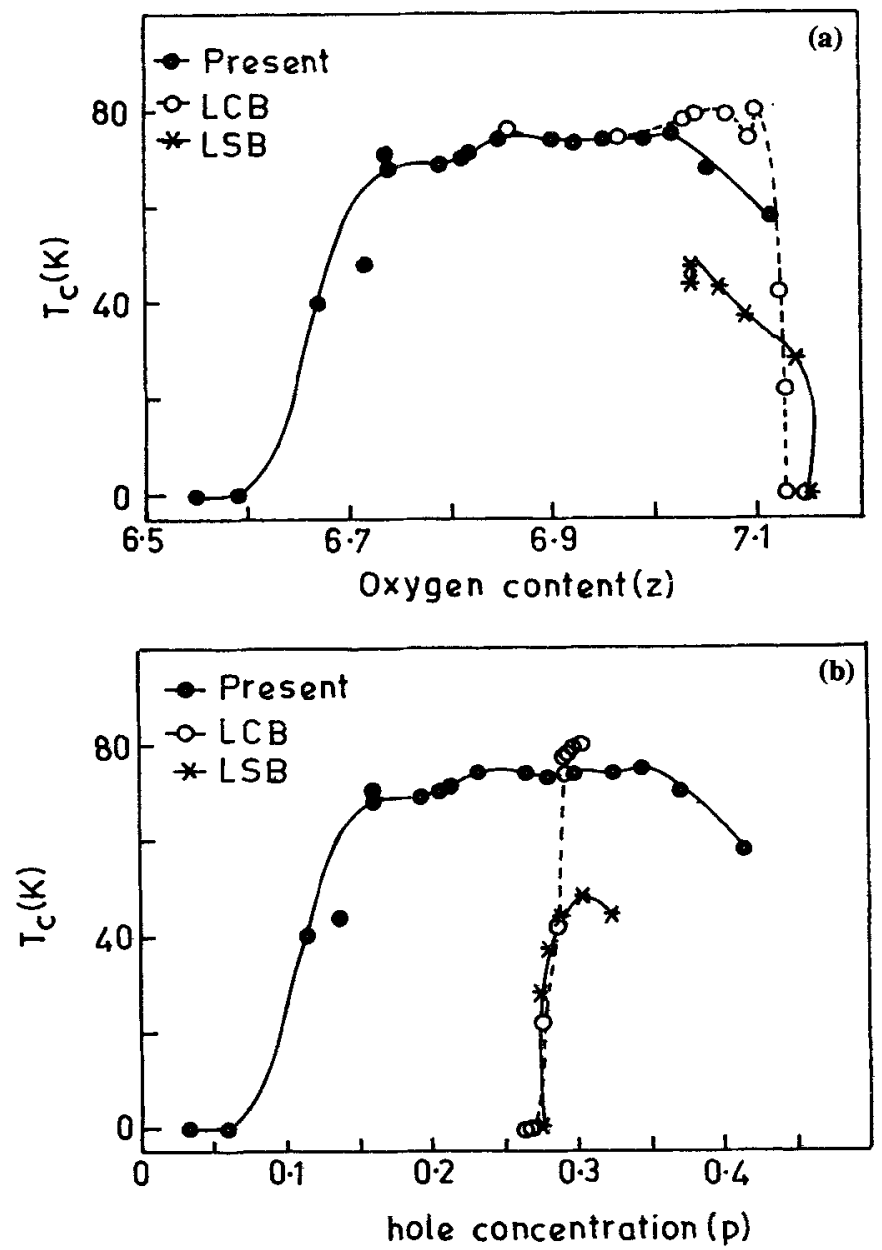

Figure 6. a. $T$ vs oxygen stoichiometry $(z)$ for $\mathrm{LC}, \mathrm{CB}, \mathrm{LCB}^{5}$ and $\mathrm{LSB}^{6}$ series and $\mathrm{b}$. $T_{\mathrm{c}}$ vs hole concentration $(p)$ for $\mathrm{LC}$, $\mathrm{CB}, \mathrm{LCB}^{5}$ and $\mathrm{LSB}^{6}$ series. z. In other words, the hole concentration increases as the amount of $\mathrm{La}^{3+}$ ions in the $\mathrm{Ba}^{2+}$ site decreases up to $x=0.5$.

In order to demonstrate the effect of $\mathrm{Ca}$ substitution in $\mathrm{La}_{1.5-x} \mathrm{Ca}_{x+y} \mathrm{Ba}_{1.5-y} \mathrm{Cu}_{3} \mathrm{O}_{z}$ on the correlation between superconductivity and hole concentration $(p)$, we have shown in figure $7, T_{\mathrm{c}}$ and $p$ vs $\mathrm{Ca}$ concentration ( $x$ or $y$ ). It is evident from figure $7 \mathrm{a}$ that both $T_{\mathrm{c}}$ and $p$ for LC series increase with increasing $x$ up to $x=0.5$ showing a correlation between $T_{\mathrm{c}}$ and $p$. For the CB series, $p$ increases with increasing $y$ up to 0.70 (figure $7 \mathrm{~b}$ ), while $T_{\mathrm{c}}$ remains nearly constant up to $y=0.50$ and thereafter it decreases for $y>0.5$ due to excess hole doping beyond an optimum value of 0.333 (table 2). This clearly shows that $\mathrm{Ca}$ acts, in both LC and $\mathrm{CB}$ series, as hole dopant.
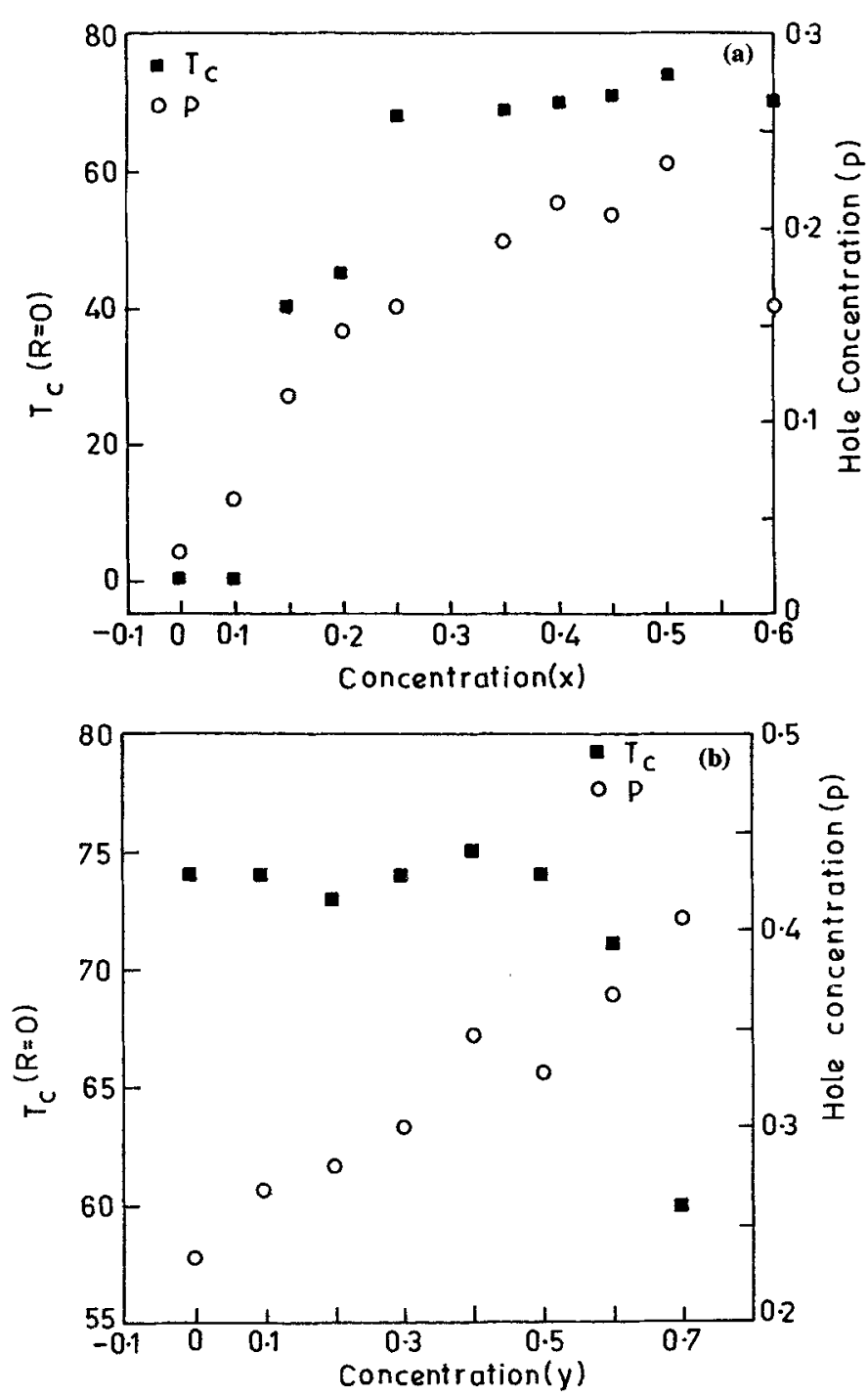

Figure 7. a. $T_{c}$ and hole concentration $(p)$ vs $x$ for $\mathrm{La}_{1.5-x} \mathrm{Ca}_{x} \mathrm{Ba}_{1.5} \mathrm{Cu}_{3} \mathrm{O}_{z}$ and $\mathrm{b} . T_{\mathrm{c}}$ and hole concentration $(p)$ vs $y$ for $\mathrm{LaCa}_{7.5+y} \mathrm{Ba}_{1.5-y} \mathrm{Cu}_{3} \mathrm{O}_{z}$. 
The observed increase in $T_{\mathrm{c}}^{R=0}$ by $\mathrm{Ca}$ substitution in $\mathrm{La}_{1.5} \mathrm{Ba}_{1.5} \mathrm{Cu}_{3} \mathrm{O}_{2}$ is explained on the basis of the oxygen effect, assuming it is real. The oxygen content, $z$, of a superconductor is directly related to the hole concentration $p$, which controls the superconductivity. The concentration of holes can be varied by varying the $\mathrm{Ca}$ doping concentration. It is evident from figure 6a that $T_{c}^{R=0}$ increases from 0 to $75 \mathrm{~K}$ as $z$ increases from 6.55 to 7.02 with corresponding increase of $x$ and $y$ from 0.0 to 0.50 (table 2). The trend is clear: both oxygen content as well as hole concentration increase as the samples are doped with higher concentrations of $\mathrm{Ca}^{2+}$ for $\mathrm{La}^{3+}$, and $\mathrm{Ba}^{2+}$. The $T_{\mathrm{c}}^{R=0}$ of $\mathrm{LC}$ and $\mathrm{CB}$ series increases with increasing $x$ and $y$, as $p$ increases up to the optimum value of 0.340 at $x+y=0.50+0.40=0.90$. Our results of LC series agree with the $T_{\mathrm{c}}$ oxygen content behaviour observed in orthorhombic $\mathrm{YBa}_{2} \mathrm{Cu}_{3} \mathrm{O}_{7-\delta}$, in which $T_{c}$ increases with increasing oxygen content from 6.50 to 6.85 (Mckinnon et al 1988).

\section{Conclusions}

Reducing the lanthanum stoichiometry in the $\mathrm{La}_{1.5-x} \mathrm{Ca}_{x} \mathrm{Ba}_{1.5} \mathrm{Cu}_{3} \mathrm{O}_{z}$ compounds, the amount of $\mathrm{La}^{3+}$ ions in the $\mathrm{Ba}^{2+}$ site is reduced, resulting in an increase in oxygen stoichiometry and hole concentration of the superconducting $\mathrm{CuO}_{2}$ layers. As a result, only one superconducting single phase, with tetragonal triple-perovskite structure, is observed for $0.0 \leq x \leq$ 0.60 which shows an increase in $T_{\mathrm{c}}^{R=0}$ from 0 to $74 \mathrm{~K}$ as $x$ increases from 0.0 to 0.50 . The superconductivity of the $\mathrm{La}_{1.5-x} \mathrm{Ca}_{x+y} \mathrm{Ba}_{1.5-y} \mathrm{Cu}_{3} \mathrm{O}_{z}$ compounds is found to correlate with the hole concentration for $0.0 \leq x \leq 0.60$ and $0.0 \leq y \leq 0.70$.

\section{Acknowledgements}

Financial support from DAE BRNS in the form of project is thankfully acknowledged. One of the authors (NAS) thanks IUC-DAEF for the award of project assistantship. The authors wish to thank Prof. Ajay Gupta and Dr V Ganesan, IUC-DAEF, for XRD measurements. NAS also appreciates the assistance in the experimental work by his colleagues Mr M V S Rao, K M Pansuria and Amish $\mathrm{G}$ Joshi. Fruitful discussions with $\mathrm{Dr} G \mathrm{~J}$ Baldha are highly appreciated.

\section{References}

De Leeuw D M, Mutsaers C A H A, Van Hal H A M, Verweij H, Carim A H and Smoorenburg H C A 1988 Physica C156 126

Engelsberg S 1991 Physica C176 451

Fu W T, Zandbergen $\mathrm{H}$ W, Van Der Beck $\mathrm{C} J$ and De Jongh L J 1988 Physica C156 133

Gunasekaran R A, Yakhmi J V and lyer R M 1993 Physica C208 1443

Katano S, Funahashi S, Hatano T, Matsushita A, Nakamura K, Matsumoto T and Ogawa K $1987 \mathrm{Jpn}$ J. Appl. Phys. 26 L1049

Leu Y D, Huang W N, Wang C M and Kao H C I 1996 Physica C261 284

Mckinnon W R, Post M L, Selwgn L S, Pleizier G, Tarascon J M, Barboux P, Greene G H and Hay G W 1988 Phys. Rev. B38 6543

Wu D S, Kao H C I, Wu M K and Wang C M 1993a Physica C214 261

Wu D S, Wang Y F, Kao H C I and Wang C M 1993b Physica C212 32

Yuan C C, Wu D S, Wang C M and Kao H C I 1996 Physica C268 128 